\title{
Usage of freeze-dried vegetable and fruit-berry powders in milkshake technology
}

\author{
Ekaterina Demina ${ }^{1 *}$, Anna Simonenkova ${ }^{1}$, Olga Luneva $^{1}$, Tatyana Bychkova $^{2}$ and \\ Elena Zaugolnikova ${ }^{1}$ \\ ${ }^{1}$ Oryol State University named after I.S. Turgenev", No. 95, st. Komsomolskaya, Oryol region, Oryol, \\ 302026, Russian Federation. \\ ${ }^{2}$ FSBEI of Higher Education K. G. Razumovsky Moscow State University of Technologies \\ and Management, st. Zemlyanoy Val, 73, Moscow, 109004, Russian Federation
}

\begin{abstract}
The paper considers the prospects for the use of freeze-dried vegetable powders in the technology of milkshakes. The main advantages of using enriching powders in the composition of functional dairy products are shown. The use of plant powders has been proven to enrich dairy products with antioxidant substances, dietary fiber, vitamins and plant protein. A significant increase in the amount of vitamins was noted - in a strawberry-raspberry cocktail, the content of vitamin $\mathrm{C}$ increased 2.5 times, $\beta$-carotene - 100 times, vitamin E - 6 times (for a carrot-pumpkin cocktail). The content of the main macro- and microelements has also increased potassium - by $15 \%$, sodium - by $29 \%$, iron - doubled, which is due to the full chemical composition of vegetable and fruit and berry powders. The use of natural plant components as flavoring additives will significantly improve the organoleptic properties of the developed dairy products.
\end{abstract}

\section{Introduction}

In the past few years, the technology of sublimation dehydration of raw materials and finished products has been successfully developed all over the world and in Russia. Freezedried products are used both as independent dishes and as raw materials for the production of fortified foods [1]. The vacuum drying method makes it possible to obtain biologically valuable products, to preserve their consumer properties and hygienic safety for a long time under unregulated temperature conditions [2,3]. Of great practical interest is the expediency of using plant raw materials obtained by freeze-drying in the technology of dairy products. First, the use of plant powders will enrich dairy products with antioxidant substances, dietary fiber, vitamins and plant protein. Secondly, it should be noted that the use of natural plant components as flavoring additives will significantly improve the organoleptic properties of the developed dairy products [4].

To date, a significant number of unique technologies for obtaining sublimation products, confirmed by patent documents, have been developed [5,6,7]. However, on the domestic market, these products are mainly represented by an assortment of products for

* Corresponding author: deminakate1@yrambler.ru 
sports and dietary nutrition, containing protein concentrates, vitamins and microelements. In many ways, this can be explained by the high cost of sublimated products, which is due to the use of modern expensive equipment, high energy consumption of the technological process and the need to use high-quality feedstock. Therefore, expanding the range of products using freeze-dried powders is an urgent task for the manufacturer.

The paper considers the possibility of using sublimation raw materials in the technology of milkshakes. The purpose of the work is the development of milkshakes enriched with freeze-dried plant powders and a comprehensive assessment of the quality of finished products.

\section{Material and methods}

The experiments were carried out in the laboratory of the Department of Food Technology and Organization of Restaurant Business, OSU named after I.S. Turgenev. The objects of the study were freeze-dried plant powders, model compositions of a milkshake, and a finished product - a milkshake. A cocktail made without the addition of freeze-dried plant powders was used as a control sample. Vegetable powders of carrots, pumpkins, beets, strawberries, raspberries, plums, and apricots were obtained using a vacuum drying apparatus [8]. The freeze-dried powders obtained in this way had good organoleptic characteristics and high quality indicators. Consistency is finely dispersed, slightly clumping when compressed, smell, color are saturated, depending on the used plant raw materials (Fig. 1).

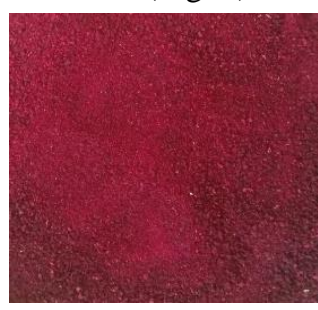

beet

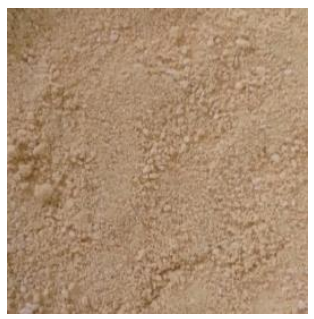

apple

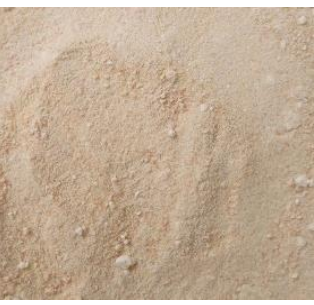

apricot

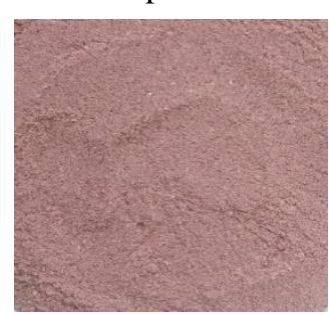

raspberry

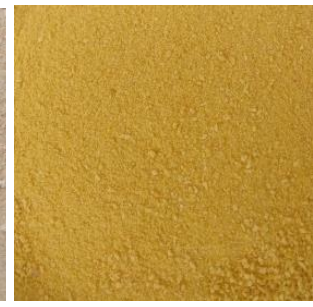

pumpkin

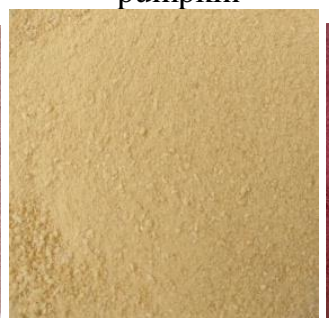

carrot

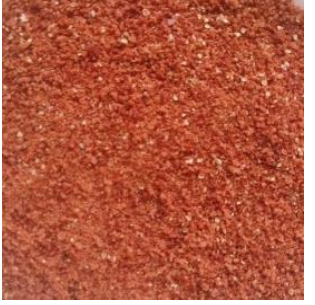

strawberry

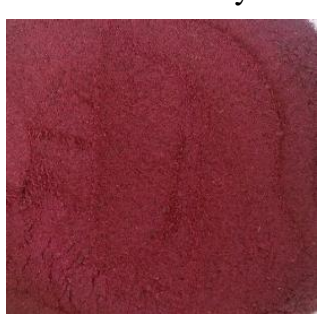

cranberry

Fig. 1. Appearance of freeze-dried vegetable and fruit-berry powders.

The mass fraction of powder moisture was determined by the standard method according to All Union State standard 28561-90; active acidity - using a pH meter "Ecotest2000"; To determine the water-binding (WBC), water-retaining (WRC), the studied powders were mixed with water in a ratio of 1: 1, 1: 5 and 1:10 and kept for 1 hour, the value of the indicator was determined every 15 minutes. When studying WBC, the powders were mixed with water in various ratios from 1: 1, 1: 5, and 1:10 and centrifuged for 10 min. at $1000 \mathrm{rpm} / \mathrm{min}$ [9]. The organoleptic assessment of the quality of powders, model compositions and the finished product was carried out using the ball method according to the developed 25-point scale, which allows us to establish the quality level. The calculation of the nutritional value was carried out taking into account the available data on the 
chemical composition of the raw materials used in milkshakes [10]. The daily requirement for basic nutrients was determined taking into account the physiological norms of consumption of basic food components $[11,12]$.

Model milkshake compositions contained milk with a fat mass fraction of $2.5 \%$, skimmed milk powder, a consistency stabilizer - gelatin, and various freeze-drying powders in an amount from 4 to $8 \%$. The ratio of the components in the model compositions was selected based on the optimal organoleptic characteristics of the finished product.

\section{Results and discussion}

It is impossible to regulate the technological process of producing milkshakes in a targeted manner without studying the functional and technological properties of the raw materials used. Vegetable raw materials are multicomponent, variable in composition and properties, which can lead to significant fluctuations in the quality of finished products. The $\mathrm{pH}$ in vegetable and fruit-berry powders varied from 3.5 to $6.1 \%$. All tested powders had good moisture binding properties. The highest water-binding capacity was found in pumpkin and carrot powders. Pumpkin powder bound water as much as possible when the ratio of powder and water is 1: 5 and 1:10, which is explained by the high content of dietary fiber in the composition of the powder $(11.5 \%)$, which binds moisture well. The lowest value is noted for black currant powder (table 1).

Table 1. Physical and chemical indicators of vegetable and fruit and berry powders.

\begin{tabular}{|l|c|c|c|c|c|}
\hline \multirow{2}{*}{\multicolumn{1}{c|}{ Powder name }} & \multirow{2}{*}{$\begin{array}{c}\text { Mass } \\
\text { fraction of } \\
\text { moisture, \% }\end{array}$} & \multirow{2}{*}{$\begin{array}{c}\text { pH of a 10\% } \\
\text { solution, \% }\end{array}$} & \multicolumn{3}{|c|}{ WBC,\% at a powder : water } \\
\cline { 4 - 6 } & & & $\mathbf{1 : 1}$ & $\mathbf{1 : 5}$ & $\mathbf{1 : 1 0}$ \\
\hline apricot & 3,0 & 4,1 & 100 & 137 & 185 \\
\hline raspberry & 4,0 & 4,9 & 100 & 156 & 239 \\
\hline strawberry & 6,7 & 4,7 & 100 & 175 & 263 \\
\hline apple & 7,2 & 4,2 & 100 & 137 & 237 \\
\hline black currant & 4,2 & 3,5 & 100 & 128 & 162 \\
\hline cranberry & 8,6 & 3,7 & 100 & 169 & 185 \\
\hline pumpkin & 7,6 & 6,1 & 100 & 436 & 769 \\
\hline carrot & 9,0 & 5,1 & 100 & 271 & 355 \\
\hline beet & 4,9 & 5,8 & 100 & 185 & 289 \\
\hline
\end{tabular}

The dynamics of changes in water-retaining capacity (Fig. 2) was generally the same for different types of powders, in the first 30 minutes the values of this indicator increased, in the next 30 minutes and until the end of the experiment the values decreased. The WRC value for pumpkin and carrot powders reached the highest value after 45 minutes. Freezedried beet and black currant powders had the minimum WRC. According to the results of the study, the optimal holding time was determined - for fruit and berry powders - 30 minutes, for vegetable powders - 45 minutes, which was taken into account in determining the technological modes for the production of milkshakes. 


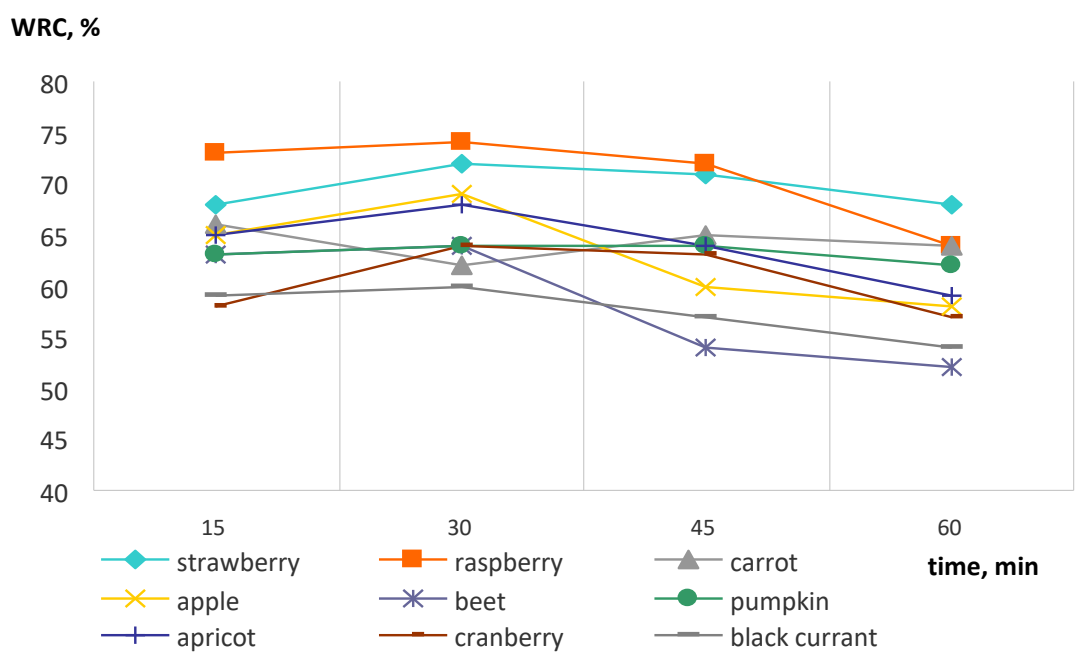

Fig. 2. Water-holding capacity of powders.

Organoleptic evaluation showed that the acceptable combinations of "milk base: powder" for a cocktail can be considered compositions containing powders of raspberries, strawberries, pumpkin, carrots, apples, beets. These compositions were characterized by balanced taste and pleasant color. Samples with cranberry, apricot and black currant powders had an excessively sour taste, which is a consequence of the low $\mathrm{pH}$ value of their $10 \%$ solutions. In the cocktail with blackcurrant powder, a flaking of consistency was recorded.

The most harmonious combinations include pumpkin powder: carrot powder, apple powder: beet powder, strawberry powder : raspberry powder. So, the model composition with the addition of carrots and pumpkin (powder ratio 1: 1) was characterized by a pleasant taste and aroma, had a yellow-orange color. In the sample with apple and beetroot powder (in a powder ratio of 3: 1), the composition acquired a fruity taste and aroma, a rich dark pink color. Strawberry and raspberry powders at a 2: 1 ratio provided a delicious flavor and creamy pink shade to the milkshake. According to the results of a complex organoleptic assessment, milkshakes received the following total points: strawberryraspberry - 24.7, apple-beet - 24.8, carrot-pumpkin - 24.7 points, which corresponds to high quality (Fig. 3, 4).

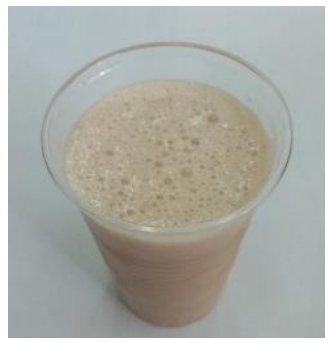

a) Strawberry-raspberry milkshake

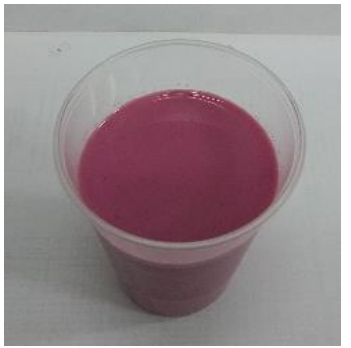

b) Apple-beet milkshake

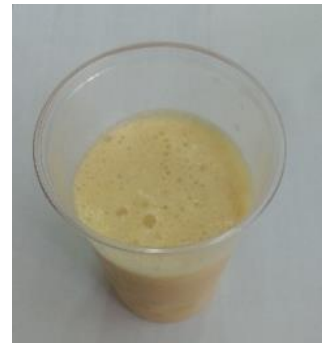

c) Carrot-pumpkin milkshake

Fig. 3. Appearance of fruit and vegetable milkshakes. 


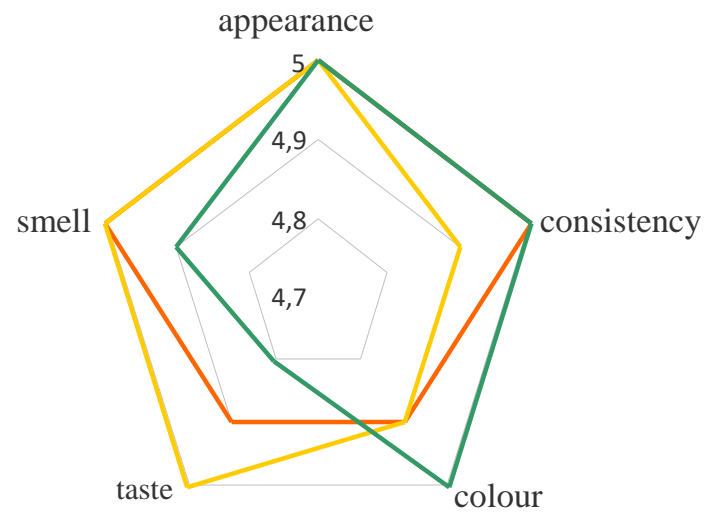

\section{— Strawberry-raspberry milkshake}

- Apple-beet milkshake

\section{Carrot-pumpkin} milkshake

Fig. 4. The results of the organoleptic evaluation of milkshakes

The obtained results of the study made it possible to develop a recipe for milkshakes, which included the following components: cow's milk $2.5 \%$ fat, skimmed milk powder, vegetable and fruit and berry powders in an amount of $4 \%$ by weight of the mixture, sugar and gelatin as a structurant.

Determination of the main physical and chemical parameters (table 2) of milkshakes showed that the developed milkshakes have a neutral $\mathrm{pH}$ level, the dry matter content exceeds the control sample by an average of $2.5 \%$. The overrun of the developed cocktails is higher, which is due to the presence of pectin and protein substances in the composition of fruit and berry powders, which determine the emulsifying and stabilizing ability.

Table 2. Physical and chemical indicators of the quality of cocktails

\begin{tabular}{|l|c|c|c|c|}
\hline \multicolumn{1}{|c|}{ Indicator name } & $\begin{array}{c}\text { Control } \\
\text { sample }\end{array}$ & $\begin{array}{c}\text { Strawberry- } \\
\text { raspberry } \\
\text { milkshake }\end{array}$ & $\begin{array}{c}\text { Apple-beet } \\
\text { milkshake }\end{array}$ & $\begin{array}{c}\text { Carrot- } \\
\text { pumpkin } \\
\text { milkshake }\end{array}$ \\
\hline Solids content,\% & 25,4 & 27,6 & 28,3 & 27,7 \\
\hline Overrun,\% & 48,4 & 49,8 & 49,2 & 50,1 \\
\hline $\mathrm{pH}$, units & 6,58 & 6,32 & 6,49 & 6,51 \\
\hline
\end{tabular}

The mass fraction of fat in finished products was $2.3 \%$. The developed milkshakes, in contrast to the control sample, contain dietary fiber (strawberry-raspberry - $0.6 \%$, applebeetroot $-0.4 \%$, carrot-pumpkin - $0.5 \%$ ). A significant increase in the amount of vitamins was noted - in the strawberry-raspberry cocktail, the content of vitamin $\mathrm{C}$ increased 2.5 times, $\beta$-carotene - 100 times, vitamin E - 6 times for the carrot-pumpkin cocktail compared to the control sample that did not contain plant components. The content of the main macro- and microelements has also increased - potassium by $15 \%$, sodium - by $29 \%$, iron twice, which is due to the full chemical composition of vegetable and fruit-berry powders. The results of calculating the daily requirement for basic nutrients when consuming $200 \mathrm{~g}$ of milkshakes are presented in Fig. 5. The highest level of satisfaction of the daily requirement was achieved for such food components as carbohydrates (16.5-18\%), vitamin $\mathrm{B}_{2}(24.8-26 \%)$, calcium (35 - 36.4\%), phosphorus (31.6 - 34.8\%), potassium (16.6 $17.8 \%)$, magnesium (11.8 - 12.6\%) when consumed $200 \mathrm{~g}$ of product. 


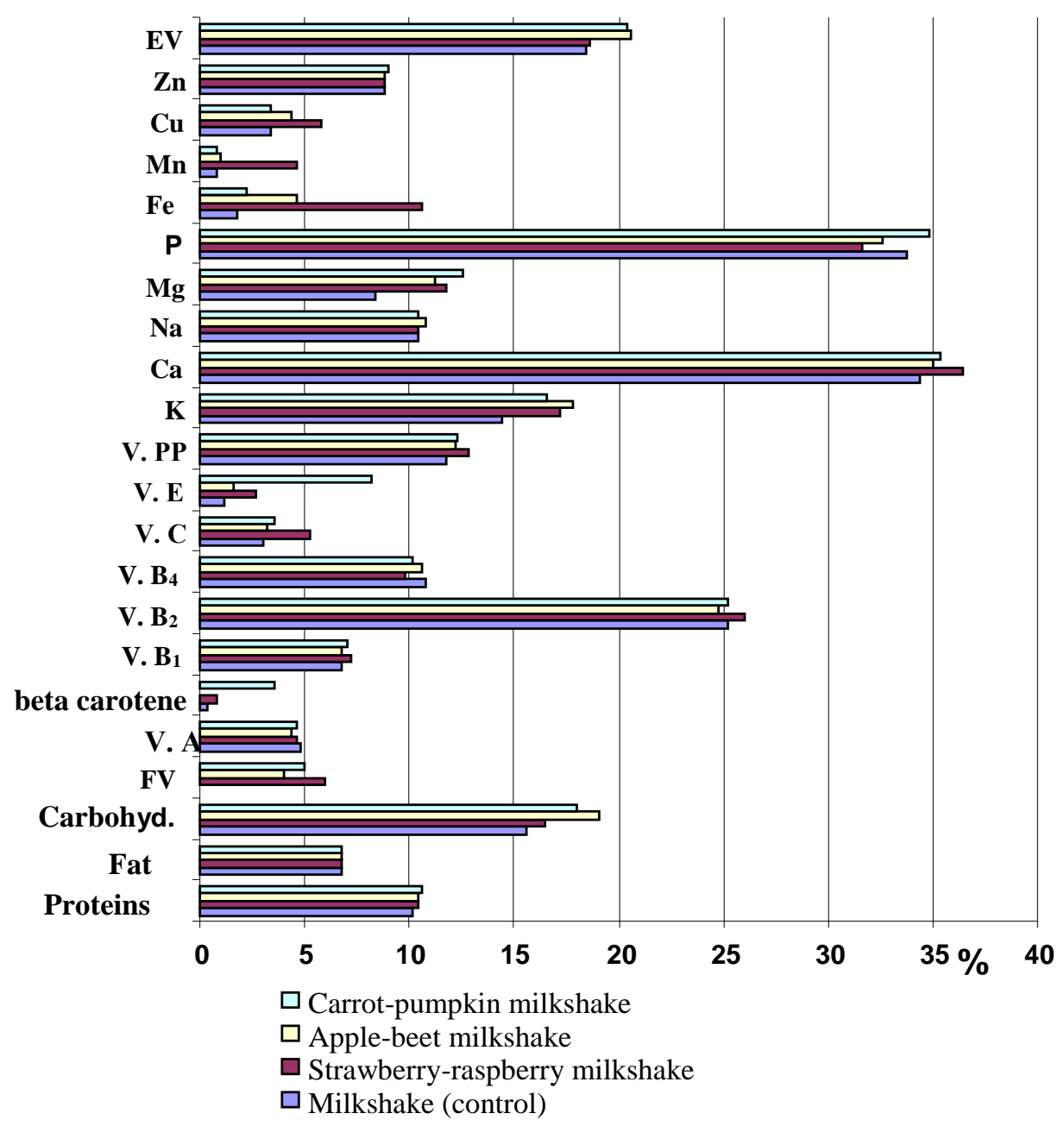

Fig. 5. The level of satisfaction of the daily physiological norm in basic nutrients, $\%$.

\section{Conclusions}

Thus, the introduction of vegetable and fruit and berry powders into the composition of milkshakes enriches the developed products with vitamins, bioflavonoids, organic acids, carotenoids, biologically active substances vital for the growth and development of a healthy person. Good organoleptic characteristics of the developed cocktails are achieved without the use of artificial flavoring and coloring substances through the use of natural enriching powders.

\section{References}

1. G.A. Donskaya, E.V. Zakharova. The use of sublimation drying concentrates in the production of functional dairy products. Dairy Industry, 1 (2013).

2. G.V. Semenov, I.S. Krasnova. Sublimation drying of food products (Moscow: DeLi plus, 2018) 
3. G.V. Semenov, N.V. Shane, T.L. Troyanova. Choice of freezing and sublimation drying modes for thermolabile objects. Izvestiya vuzov. Food technology. 5-6 (2002)

4. E.N. Demina, O. V. Safronova The use of sublimation raw materials in the technology of dairy products// Topical issues of the dairy industry, intersectoral technologies and quality management systems: a collection of scientific papers. Vol. 1 (Moscow: Publishing house and printing house "Sad-Izdat", 2020)

5. I.F. Gorlov, I.M. Osadchenko, O.P. Serova [and etc.]. A method of obtaining a curdvegetable product: RF patent No. 2370045. (2009)

6. I.F Gorlov, O.P. Serova, E.N. Mashkina [and etc.] A method of obtaining a milk dessert: RF patent No. 2356232. (2009)

7. S. Peterson, F. Welch, T. Burkholder [et al.]. Freeze-dried, aerated milk or milk replacement compositions and methods for their preparation: RF patent No. 2491823. (2013)

8. S.A. Ermakov. Method of vacuum freeze drying with convective heat energy supply and freeze drying unit: RF patent No. 2420215. (2011)

9. S. Ya. Koryachkina, O. L. Ladnova, O.A. Godunov, E.N. Kholodova The use of finely dispersed vegetable and fruit-berry powders in the production of food concentrates for sweet dishes, Technology and commodity science of innovative food products, 2 (31) (2015).

10. Chemical composition of Russian food products (Moscow: DeLi print, 2002).

11. Norms of physiological needs for energy and nutrients for various groups of the population of the Russian Federation. Methodical recommendations. (Moscow: Federal Center for Hygiene and Epidemiology of Russian Federal State Agency for Health and Consumer Rights 2009).

12. V.I. Karpov, N.M. Portnov, I.A. Nikitin, Y.I. Sidorenko, I.V. Zavalishin, S.M. Petrov, N.M. Podgornova, M.Y. Sidorenko, S.V. Shterman, International Journal of Advanced Computer Science and Applications. 10 (11), 317-322 (2019). 